\title{
Conflictividad social y orden público en Toledo, durante el Primer Bienio republicano (1931-1933)
}

\author{
ÁNGEL TORREJón \\ Doctorando Dpto. de H. ${ }^{a}$ Contemporánea. UNED \\ Jefe del Departamento de Geografía e Historia del IES \\ «Miguel Hernández» de Ocaña (Toledo)
}

\section{Social conflicts and public order in Toledo during the first republican two years (1931-1933) \\ RESUMEN SUMMARY}

Entre 1931 y 1933, la provincia de Toledo se ve sacudida por una sucesión de conflictos de carácter político y social que, tomados en conjunto, adquieren la morfología de una auténtica lucha interclasista. En esta dinámica de enfrentamiento, las capas sociales menos favorecidas reafirmaron su conciencia de clase y asentaron su estructura institucional. Simultáneamente, el bloque de la derecha sentía la amenaza que, para su tradicional posición dominante en el campo toledano, representaba la legislación social de los gobiernos del primer bienio republicano. El coste en víctimas mortales de esta tensión social fue muy elevado, uno de los más elevados de las provincias españolas. A ello colaboró decisivamente la política de orden público del nuevo régimen republicano que se expresó a través de la cuestionable actuación de los diversos gobernadores civiles.

\section{PALABRAS CLAVE}

Primer Bienio, Segunda República, Toledo, conflictos sociales, orden público, Guardia Civil, Gobernadores.
Between 1931 and 1933, the province of Toledo was shaken by a sucession of political and social conflicts which as a whole took the shape of a real class struggle. In this system of confrontation, the less favoured social strata reasserted its class consciousness and laid down its institutional structure. At the same time the right wing-bloc perceived a threat from the social laws carried out by the republican governments during the first two-year period of its traditional dominant position in Toledan farming. The cost in mortal victims of this social tension was very high, one of the highest in all Spanish provinces. The public order policy applied by the new republican regime manifested by the questionable behaviour of the civil governors contributed in a decisive way to such tensions.

\section{KEY WORDS}

Primer Bienio, Segunda República,

Toledo, conflictos sociales, orden público, Guardia Civil, Gobernadores. 


\section{INTRODUCCIÓN}

En la historiografía española contemporánea no son escasos los estudios sobre las agitaciones sociales en la Segunda República. Se trata, en general, de consistentes aportaciones de historia regional o provincial que suelen referirse al ámbito geográfico de las comunidades andaluza y extremeña ${ }^{1}$; todos ellos constituyen, sin duda, elementos esenciales para alcanzar una interpretación completa de la cuestión. No obstante, adolece ese compendio historiográfico, a nuestro entender, de aportaciones referidas a provincias hasta ahora olvidadas en dichos estudios. $\mathrm{E}$ caso de Toledo es, en ese sentido, paradigmático. Entre abril de 1931 y noviembre de 1933 se produjeron en la provincia 32 muertes en incidentes de carácter social o político. Se trata de cifras realmente llamativas para una población de sólo 489.396 personas. ${ }^{2}$ Estos datos, a falta de un estudio comparado con otras regiones, nos permiten señalar a esta provincia como una de las que padecieron los conflictos político-sociales más intensos de ese periodo. Cuantitativa y cualitativamente, esa cadena de sucesos violentos adoptó un carácter pre-revolucionario que puso en cuestión la estructura social dominante. De esa manera, se impugnaba también el tradicional sistema de relaciones de dependencia que había imperado en el campo manchego durante siglos.

En sentido amplio, las muestras de conflictividad que vamos a analizar en las siguientes páginas, conforman un evidente escenario de enfrentamiento interclasista. La extinta Monarquía había arrastrado consigo a una parte sustancial del anquilosado esquema social en el que se apoyaba, e inmediatamente se pudo comprobar que las masas trabajadoras no estaban dispuestas a dejar pasar la oportunidad de impulsar transformaciones de gran alcance. Cada grupo social se situó ante las nuevas circunstancias; así, mientras el bloque de derechas se organizó defensivamente en torno a los propietarios agrícolas y dos principios básicos: el agrarismo y el catolicismo ${ }^{3}$, el proletariado rural percibió que, por primera vez, el aparato del Estado no le era hostil y, cada vez más convencido de su fuerza real, tomó conciencia de su posición como clase, con intereses específicos diferenciados de otros segmentos del proletariado 4 .

1 Entre otras, véanse las obras de FRANCISCO COBO ROMERO, De campesinos a electores: modernización agraria en Andalucía, politización campesina y derechización de los pequeños propietarios y arrendatarios: el caso de la provincia de Jaén, 1931-1936, Madrid, Biblioteca Nueva, 2003; MANUEL PEREZ YRUELA, La conflictividad campesina en la provincia de Córdoba (1931-1936), Madrid, Servicio de Publicaciones Agrarias, 1979; MANUEL TUÑÓN DE LARA, Luchas obreras y campesinas en la Andalucía del siglo XX. Jaén 1917-1920. Sevilla 1930-1932, México, Siglo XXI, 1978. JOSÉ MANUEL MACARRO VERA, Socialismo, República y revolución en Andalucía: (1931-1936), Sevilla, Universidad, 2000. Dentro del ámbito de Castilla-La Mancha y, por sus elementos comunes con Toledo, es recomendable la obra de M. ${ }^{\text {a }}$ PAZ LADRÓN DE GUEVARA, La esperanza republicana: reforma agraria y conflicto campesino en la provincia de Ciudad Real (1931-1936), Ciudad Real, Diputación, 1993.

2 INE. Series históricas de población. Censo de 1930.

3 RODRÍGUEZ LÓPEZ-BREA, C., «Dos claves de la política de Acción Popular durante la II República: agrarismo y catolicismo. El ejemplo de Toledo» en TUSELL, J., GIL PECHARROMÁN, J. y MONTERO, F., Estudios sobre la derecha española contemporánea. Madrid, UNED, 1993, pp. 527-547.

4 Un atrayente análisis en torno a la existencia o no de conciencia de clase en el campesinado y el proceso de adquisición de la misma, lo podemos encontrar en EDUARDO SEVILLA-GUZMÁN, La evo- 


\section{LA PROVINCIA EN LLAMAS}

La historia de la provincia de Toledo durante los dos primeros años republicanos se halla plagada de incidentes violentos, en los que los grupos políticos y sociales midieron sus fuerzas. Desde la que se considera primera ocupación de tierras durante la Segunda República ${ }^{5}$, hasta el asesinato de un obrero sindicalista católico en Los Navalmorales ${ }^{6}$, los conflictos sociales y políticos con distinto grado de violencia se extendieron por todas las comarcas toledanas. El recurso violento pasó a ser un instrumento esencial en la política de masas ${ }^{7}$. Su uso se convirtió en algo cotidiano, que hallaba justificación desde todos los puntos del espectro político, exceptuando quizás al sector de la débil burguesía republicana. El tratamiento de estos acontecimientos en la prensa provincial nos ayuda a entender la intensidad con la que alteraron la vida diaria de la provincia. Incluso se crearon secciones fijas para informar sobre «la situación social de la provincia».8

En las siguientes páginas abordaremos esos sucesos en un doble aspecto: en primer lugar, como un estudio cuantitativo y creemos próximo a la exhaustividad, que recoge todos los conflictos en cuestión; en segundo lugar analizaremos la política de orden público, con especial hincapié en la actuación de los gobernadores civiles.

En el Mapa 1 mostramos la distribución comarcal de las víctimas mortales y heridos por arma de fuego o arma blanca consecuencia de esos sucesos. Las cifras más elevadas, 23 víctimas mortales, se registran en las comarcas de La Mancha, La Sagra y Torrijos. Se trata de tres zonas con escasa presencia del latifundio, tierras aceptablemente cultivadas y con predominio de la pequeña propiedad ${ }^{9}$. Por el contrario, en los espacios latifundistas clásicos de los Montes de Toledo, la Campana de Oropesa o La Jara sufren solamente cuatro muertes. Aparece así la primera contradicción que matiza una de las tesis habituales de la historiografía española contemporánea sobre el tema, a saber, que la violencia en el campo tenía su origen en el injusto reparto de la tierra, es decir, el latifundismo actúa como catalizador de esa violencia. Sin desechar ese factor de relevancia indiscutible, se trata de delimitar su

lución del campesinado en España, Barcelona, Península, 1979. De especial relevancia nos parece el Capítulo IV, en el que estudia las interacciones mutuas entre la conflictividad campesina y la estratificación social.

5 El Castellano, n. ${ }^{\circ} 6884,20 / \mathrm{V} / 1931$. En Yuncos roturan un terreno sin permiso de su propietario en la finca Arroyo Vedado, propiedad de Ricardo Aguilar. Cuatro obreros realizaron esas tareas por indicación de las autoridades municipales. El terreno afectado apenas llegaba a cuatro metros por ambos lados del arroyo. Salieron de ella pacíficamente.

6 Idem, n. ${ }^{\circ} 7655,28 / \mathrm{XI} / 1933$. Se informa de que Gil Robles inicia una colecta en beneficio del afiliado al sindicato católico Acción Obrerista, Reyes Redondo, vecino de Los Navalmorales y que fue asesinado por disparos de escopeta la víspera de las elecciones. Fueron detenidos como supuestos culpables los hermanos Heriberto y León Arteaga, calificados como «socialistas o extremistas de ese pueblo".

7 GONZÁLEZ CALLEJA, E., El máuser y el sufragio. Orden público, subversión y violencia política en las crisis de la Restauración (1917-1931), Madrid, CSIC, 1999, p. 641.

8 Eso ocurre, por ejemplo, en el periódico El Castellano. Pero también la prensa de Madrid, con los periódicos El Sol y El Debate a la cabeza, se hará eco de los conflictos más graves.

9 CARRIÓN CARRIÓN, Pascual, Los latifundios en España, Barcelona, Ariel, 1975, p. 135. 
incidencia e identificar otras variables no estructurales que intervienen en el fenómeno. Pensemos que la injusta estructura de propiedad de la tierra en la región es una constante que hunde sus raíces en el Antiguo Régimen y que se acentúa durante la fase desamortizadora. Así pues, el «problema de la tierra» era parte consustancial de la vida política, social y económica de la provincia desde hacía siglos, y sin embargo, nunca se había llegado a procesos revolucionarios, ni siquiera a conflictos sociales de alguna importancia. ¿Qué factores nuevos actuaron en Toledo durante el primer bienio para confluir en esa fase de conflictividad desconocida hasta entonces? ${ }^{10}$ No son estas breves páginas el lugar adecuado para aportar una tesis global sobre la cuestión, nos limitaremos a proponer algunos elementos de interés que bien podrían ayudar modestamente a configurar un marco global.

Siguiendo con el análisis de la distribución comarcal de víctimas violentas, apuntemos que, por lo que se refiere a La Mancha toledana, se contabilizan 13 muertos y 17 heridos, destacando el peso que en el saldo trágico tuvieron los sucesos de Corral de Almaguer, en septiembre de 1931, y los de Villa de Don Fadrique, en julio de 1932, con cinco y tres víctimas mortales respectivamente. En esta comarca concreta tendríamos que valorar la dependencia de una agricultura dominada por el olivo y la vid ${ }^{11}$, con importante demanda de mano de obra estacional y con nulas alternativas productivas que pudieran paliar los efectos de las malas cosechas. Complementaba el cuadro un sector patronal que utilizaba sabiamente y sin piedad su dominio del mercado de trabajo. En ese caldo de cultivo, era lógico que el proletariado agrícola iniciase un proceso de toma de conciencia política que convirtió a la zona en uno de los radios más sólidos del Partido Comunista en todo el país. Desde Villa de Don Fadrique, el PCE extendía su influencia a toda la comarca, trasmitiendo una concepción revolucionaria que fue percibida como una amenaza por las "gentes de orden». A partir de ahí se entenderían los excesos represivos en la comarca manchega, que concluyeron en una verdadera matanza de campesinos. Con respecto a los territorios de Torrijos y La Sagra, donde se produjo también un número destacado de víctimas, 10 muertos y 22 heridos, la explicación tendría una doble vertiente: la cercanía de Madrid y un poblamiento más denso. Desde la capital del Estado llegaban fácilmente a esas tierras las ideas socialistas, comunistas y anarquistas, acompañadas de las últimas noticias de la efervescente vida política de la metrópoli. Se impregnaban así las capas obreras del sustrato ideológico imprescindible para hacer frente a las fuerzas de la clase dominante. Unamos a ello el factor de una alta densidad de población, con presencia de un proletariado más culto ${ }^{12}$ y desarrollado que poseía instrumentos de protección y defensa superiores a los existentes en otras comarcas. La estrecha y cercana red de instituciones controladas por los partidos de iz-

10 PÉREZ YRUELA, M., op. cit. p. 111. Refiriéndose a la provincia de Córdoba, señala como elementos diferenciales los siguientes: mayor poder de negociación de las masas obreras, mejores expectativas de éxito y mayor contenido ideológico.

11 CARRIÓN CARRIÓN, P., op.cit. p 135.

12 Boletín Instituto de Reforma Agraria (BIRA), «... la región de la Sagra, la más rica, la más fértil, la más adelantada en cultivo es aquella en la cual el obrero vive mejor y es más culto...», p. 718. 
quierdas, desde los ayuntamientos a las sociedades obreras, aseguraba una comunicación fluida de las ideas proletarias y la consolidación de una conciencia de clase cada vez más depurada.

\section{MORFOLOGÍA DE LOS CONFLICTOS}

Las acciones violentas del proletariado adquirieron una doble perspectiva: por un lado recurrieron a los instrumentos clásicos que ya habían sido utilizados durante la Dictadura, como ocupaciones de fincas, destrucciones de maquinaria, incendios de cosechas o talas de árboles; y por otro introdujeron innovaciones, como la insurrección armada hasta entonces desconocida en tierras toledanas ${ }^{13}$. Las elecciones del 12 de abril de 1931 habían producido en muchos pueblos de la provincia un vuelco en el dominio de los resortes del poder municipal. De un día para otro, los que eran perseguidos por su condición de extremistas revolucionarios pasaban a hacerse cargo de las alcaldías. Desde esas nuevas posiciones, y entusiasmados con las expectativas que ofrecía la nueva era republicana, las organizaciones de la izquierda adoptaron medidas tendentes a mejorar la situación económica de las masas campesinas. Pero en ese camino de reformas habrían de enfrentarse con los poderes fácticos que todavía mantenían un peso considerable en el mundo rural. Era frecuente, por ejemplo, que los comandantes de puesto de la Guardia Civil se mostrasen reacios a reconocer la autoridad de los alcaldes socialistas, ${ }^{14}$ o prestos a discutir su gestión ${ }^{15}$. Casos similares ocurrieron con la aplicación de la legislación del Gobierno Provisional. Con todas sus limitaciones, estas medidas alteraban las relaciones de producción en el campo, por lo que fueron boicoteadas por los propietarios. Cuestiones como el respeto de las bases de trabajo o el sistema de contratación se convirtieron en principios básicos de la política municipal ${ }^{16}$. Mención aparte merece lo concerniente a la aplicación de la Ley de Términos. Concebida como una herramienta para impedir el control que los propietarios tenían del mercado laboral, acabó convirtiéndose en motivo de división entre los trabajadores, además de una alarmante muestra de insolidaridad entre ellos. Las fuentes documentales nos ofrecen repetidos ejemplos: obreros de un pueblo que expulsan a otros, que impiden contratar a parados de localidades vecinas ${ }^{17} \mathrm{O}$

${ }_{13}$ ARÓSTEGUI, J., GÓNZALEZ CALLEJA, E. y SOUTO, S., «La violencia política en la España del siglo XX» en Cuadernos de Historia Contemporánea, n. ${ }^{\circ} 22,2000$, pp. 71-80.

${ }_{14}$ Archivo Histórico Nacional-Madrid (AHN-M), Sección Gobernación, leg. 39A. Guardia Civil. Se pueden leer varios comunicados de alcaldes, como los de Mesegar y Talavera, quejándose de falta de respeto por parte de los guardias. En Talavera llegaron a dimitir el alcalde y los concejales socialistas por enfrentamientos con el capitán de la Guardia Civil.

${ }_{15}$ El Heraldo de Toledo, 14/VII/1932. El alcalde de Las Herencias se ve presionado por el cabo de la Guardia Civil que cuestiona decisiones estrictamente políticas.

${ }_{16}$ AHN-M, leg. 6A. Cuestiones sociales, exp. 21, 26 y 61 . Se recogen multitud de quejas enviadas por alcaldes y sociedades obreras denunciando la postura obstruccionista de los patronos. Aparecen asimismo, casos de multas impuestas a estos últimos por el gobernador civil.

17 El Castellano, 27///1932. En Borox existía una bolsa de más de 400 parados que podrían trabajar en las vegas vecinas de Seseña y Aranjuez pero no se les permitía. 
que se niegan a trabajar con los que no son sus convecinos ${ }^{18}$. Conflictos todos ellos difíciles de entender desde nuestra perspectiva actual y que sólo se justifican por el estado de miseria que sufría el proletariado. En consecuencia, frustrados por la ineficacia de los decretos sobre el campo y ansiosos por cambiar una situación que consideraban injusta, los partidos y organizaciones obreros recurrieron a métodos de lucha más inmediatos. Por toda la provincia se multiplicaron las ocupaciones de fincas, que alternaban con otras acciones menos controladas como la tala de árboles, la apropiación de cosechas o la caza furtiva ${ }^{19}$. Pero estas acciones obreras, lejos de ser eficaces, sólo sirvieron para aumentar la conciencia reivindicativa de las masas campesinas y, en otro sentido, fueron aprovechadas por los propietarios agrarios para consolidar su tesis de que Toledo estaba dominado por la anarquía. Lo cierto es que esta conflictividad venía a confirmar el fortalecimiento de la izquierda y la exaltación de la violencia como método de acción política.

En esa situación, sectores de la izquierda radicalizada (en Toledo esencialmente el PCE) dieron un paso más en el camino de la violencia, y optaron por la estrategia de la insurrección armada, si bien sólo de manera incipiente y limitada. Se trataba de un camino sin salida, puesto que era evidente la imposibilidad de llegar por estos métodos al triunfo definitivo del proletariado ${ }^{20}$.

Cuadro 1. Distribución por fechas y localidades de los muertos producidos en incidentes de carácter social o político durante el primer bienio republicano

\begin{tabular}{|l|c|c|c|l|}
\hline \multicolumn{1}{|c|}{ Localidad } & Fecha & $\begin{array}{c}\text { Propietarios, } \\
\text { Guardias,... }\end{array}$ & $\begin{array}{c}\text { Campesinos, } \\
\text { obreros, } \\
\text { sindicalistas }\end{array}$ & \multicolumn{1}{|c|}{ Descripción } \\
\hline $\begin{array}{l}\text { Villafranca de } \\
\text { los Caballeros }\end{array}$ & $08 / 06 / 1931$ & & 1 & $\begin{array}{l}\text { Asesinado guardia municipal } \\
\text { por sereno de Agrupación } \\
\text { Agraria incitado por patronos. }\end{array}$ \\
\hline Santa Olalla & $22 / 06 / 1931$ & & 1 & $\begin{array}{l}\text { Matan a un conductor por } \\
\text { creer que había provocado } \\
\text { accidente en mitin de } \\
\text { Ballester Gozalvo, alcalde de } \\
\text { Toledo. }\end{array}$ \\
\hline Urda & $01 / 09 / 1931$ & & 1 & $\begin{array}{l}\text { Guardia Civil dispara contra } \\
\text { cazadores. }\end{array}$ \\
\hline $\begin{array}{l}\text { Corral de } \\
\text { Almaguer }\end{array}$ & $21 / 09 / 1931$ & & 5 & $\begin{array}{l}\text { Guardia Civil dispara contra } \\
\text { campesinos. }\end{array}$ \\
\hline
\end{tabular}

(Continúa)

${ }^{18}$ El Castellano, 2///1933. En Villaluenga los obreros de la fábrica de cemento se negaron a trabajar con los procedentes de Yuncler y Cobeja. El conflicto se complicó hasta el punto de ser necesaria la protección de los obreros foráneos por la guardia civil.

19 De la consulta del AHN-M y de la prensa local he recopilado más de 200 referencias a incidentes de este tipo.

${ }^{20}$ Véase UCELAY-DA CAL, E., TAVERA GARCÍA, S.: «Una revolución dentro de otra» en Ayer, n. ${ }^{\circ}$ 13, pp. 138-140. 
Conflictividad social y orden público en Toledo, durante el Primer Bienio republicano...

(Continuación)

\begin{tabular}{|c|c|c|c|c|}
\hline Localidad & Fecha & $\begin{array}{l}\text { Propietarios, } \\
\text { Guardias,... }\end{array}$ & $\begin{array}{l}\text { Campesinos, } \\
\text { obreros, } \\
\text { sindicalistas }\end{array}$ & Descripción \\
\hline Chozas & $30 / 09 / 1931$ & & 1 & $\begin{array}{l}\text { Guardia Civil dispara contra } \\
\text { campesinos en } \\
\text { enfrentamiento. }\end{array}$ \\
\hline Talavera & $31 / 10 / 1931$ & & 1 & $\begin{array}{l}\text { Guardia Civil dispara contra } \\
\text { cazadores que invaden finca. }\end{array}$ \\
\hline Quero & $25 / 02 / 1932$ & 1 & & $\begin{array}{l}\text { Miembros Sociedad Obrera } \\
\text { disparan contra el cabo de } \\
\text { serenos. }\end{array}$ \\
\hline Toledo & $07 / 03 / 1932$ & 2 & & $\begin{array}{l}\text { Muerte de dos guardias de } \\
\text { asalto en la primera } \\
\text { intervención. }\end{array}$ \\
\hline Lucillos & $15 / 05 / 1932$ & & 1 & $\begin{array}{l}\text { Campesinos disconformes } \\
\text { con las bases disparan contra } \\
\text { otro que está trabajando. }\end{array}$ \\
\hline Cabañas & $07 / 07 / 1932$ & & 1 & $\begin{array}{l}\text { Muerte del secretario de los } \\
\text { socialistas locales. }\end{array}$ \\
\hline $\begin{array}{l}\text { Villa de } \\
\text { D. Fadrique }\end{array}$ & $08 / 07 / 1932$ & 2 & 2 & $\begin{array}{l}\text { Mueren un guardia y un } \\
\text { propietario. GC dispara contra } \\
\text { campesinos. }\end{array}$ \\
\hline $\begin{array}{l}\text { Real de } \\
\text { S. Vicente }\end{array}$ & $08 / 08 / 1932$ & 1 & & $\begin{array}{l}\text { Muerto un propietario tras } \\
\text { disparar contra el alcalde } \\
\text { socialista. }\end{array}$ \\
\hline Fuensalida & $08 / 10 / 1932$ & & 2 & $\begin{array}{l}\text { Guardia Civil dispara contra } \\
\text { campesinos. }\end{array}$ \\
\hline Villatobas & $15 / 05 / 1932$ & & 1 & $\begin{array}{l}\text { Obrero dispara contra otro por } \\
\text { una discusión sobre las bases } \\
\text { de trabajo. }\end{array}$ \\
\hline Quero & $24 / 11 / 1932$ & & 1 & $\begin{array}{l}\text { Disparan contra obreros } \\
\text { socialistas. }\end{array}$ \\
\hline $\begin{array}{l}\text { Alcolea } \\
\text { de Tajo }\end{array}$ & $15 / 04 / 1933$ & & 1 & $\begin{array}{l}\text { Propietarios disparan contra } \\
\text { obreros en un mitin socialista. }\end{array}$ \\
\hline Hormigos & $13 / 07 / 1933$ & & 1 & $\begin{array}{l}\text { Propietarios matan a obrero } \\
\text { que roba garbanzos. }\end{array}$ \\
\hline Talavera & $13 / 07 / 1933$ & & 1 & $\begin{array}{l}\text { Muerte en una reyerta de un } \\
\text { funcionario de la Secretaría } \\
\text { de Jurados Mixtos. }\end{array}$ \\
\hline Villaseca & $17 / 07 / 1933$ & & 3 & $\begin{array}{l}\text { Disparan en una reyerta } \\
\text { contra obreros, uno de ellos } \\
\text { un concejal. }\end{array}$ \\
\hline
\end{tabular}

(Continúa) 
(Continuación)

\begin{tabular}{|l|c|c|c|l|}
\hline \multicolumn{1}{|c|}{ Localidad } & Fecha & $\begin{array}{c}\text { Propietarios, } \\
\text { Guardias,... }\end{array}$ & $\begin{array}{c}\text { Campesinos, } \\
\text { obreros, } \\
\text { sindicalistas }\end{array}$ & \multicolumn{1}{|c|}{ Descripción } \\
\hline Mazarambroz & $19 / 07 / 1933$ & & 1 & $\begin{array}{l}\text { Aparece muerto un obrero } \\
\text { que días antes había } \\
\text { penetrado en la finca para } \\
\text { cazar. }\end{array}$ \\
\hline $\begin{array}{l}\text { Los } \\
\text { Navalmorales }\end{array}$ & $28 / 11 / 193$ & & $\begin{array}{l}\text { Asesinan obrero afiliado } \\
\text { sindicato derechista Acción } \\
\text { Obrerista. }\end{array}$ \\
\hline TOTALES & & 7 & 25 & \\
\hline
\end{tabular}

FUENTE: Elaboración propia ${ }^{21}$.

No obstante, las organizaciones obreras de varios pueblos adoptaron, de forma más o menos sistemática, técnicas y tácticas que iban más allá del clásico esquema de lucha. Así por ejemplo hubo casos en que los obreros se enfrentaron a la guardia civil, reaccionando de forma espontánea a situaciones que consideraban injustas ${ }^{22}$.

Todos estos acontecimientos se contemplaban desde la derecha política, y sobre todo por los propietarios agrícolas, como una demostración del estado de anarquía en que vivía la provincia. Ya desde el inicio de la República, estos grupos habían desencadenado una estrategia de boicot que, según se incrementaba la corriente violenta, transformaron en un arma de autodefensa. Perdido el control político, y ante la amenaza de perder también el poder económico, las clases dominantes ya no dudaron en actuar contra la República. El complejo conglomerado de la derecha toledana desencadenó una ofensiva obstruccionista que adoptó formas muy diversas. Entre otros recursos, disponía de herramientas tan poderosas como la capacidad de decidir quién trabajaba y quién no. Por eso, impedir

21 La contabilización corrige al alza los datos que proporciona RUIZ ALONSO, J.M., La Guerra Civil en la provincia de Toledo (I). Ciudad Real, Biblioteca Añil, 2004, p. 39, que habla de «entre 20 y 23 campesinos muertos y más de 35 heridos de bala» a los que añade 5 muertos entre propietarios y guardias civiles o de asalto. A mis cifras de muertos que aparecen en el Cuadro 1 habría que añadir más de 60 heridos.

22 La prensa local y el AHN-M recogen varios incidentes de ese tipo. El día 8/10/1932, El Castellano habla de los sucesos de Fuensalida, donde mueren dos campesinos por disparos de la Guardia Civil cuando los vecinos intentan asaltar el Ayuntamiento, lugar en el que se custodiaba a un detenido y a quien pensaban que estaban torturando. En el mismo periódico, el día 12/12/1932, en Cebolla, el pueblo se enfrenta a los disparos de la Guardia Civil para impedir que seis campesinos detenidos por desarmar a dos guardas fueran trasladados al juzgado. También en el AHN-M encontramos referencias a duros enfrentamientos entre campesinos y Guardia Civil. A lo largo del mes de marzo de 1932 hallamos cuatro comunicaciones con el Ministerio que hablan de quemas de casas y luchas con la guardia civil, así como de las demandas de ayuda e investigación por parte de propietarios y del diputado Dimas Madariaga. Finalmente el gobernador informa al Ministro de que el pueblo se encuentra en la anarquía. 
la contratación de obreros afiliados a los sindicatos de izquierda o pertenecientes a las Sociedades Obreras fue una constante en todo el campo toledano ${ }^{23}$. Cuando se publicaron los decretos de Largo Caballero, la relación de fuerzas en el campo se vio sustancialmente alterada a favor de los obreros. Entonces los empresarios respondieron incumpliendo reiteradamente esa legislación, en especial lo que se refería a las «bases de trabajo». Fue esta cuestión, junto con el incumplimiento de la ley de Términos, el origen de una infinidad de huelgas, asambleas, encierros y otros incidentes en toda la provincia. Así consta en la documentación del Archivo Histórico Nacional de Madrid (AHN-M), donde se recogen las demandas de alcaldes, sindicatos y Sociedades Obreras. El asunto debió ser de tal relieve que desde el Gobierno Civil se vieron forzados a imponer multas a algunos propietarios ${ }^{24}$. Pero el mejor utillaje con que contaba la derecha para su batalla contra la izquierda toledana era la Guardia Civil. Los propietarios y el instituto armado mantenían una relación de interdependencia desde su fundación. Con frecuencia los terratenientes costeaban los gastos de instalación y mantenimiento de cuarteles en sus tierras y la Benemérita les correspondía defendiendo sus intereses. Desde las páginas de El Castellano, principal órgano de prensa de la derecha provincial, les organizaban homenajes, recolectaban fondos para huérfanos o heridos, ensalzaba su papel como garantes del orden establecido y, en definitiva, obtenían el apoyo de una institución que debería haber permanecido neutral. También era habitual que los prohombres de la derecha provincial y nacional mantuvieran una política de constante adulación hacia el instituto armado. Así, los diputados por Toledo Dimas Madariaga y Ramón Molina se turnaban en la publicación de artículos laudatorios hacia la institución, y recurriendo a cualquier excusa coyuntural, José María Gil Robles, su líder político, hacía uso de su mejor retórica para encomiarlo:

La Guardia Civil es la institución que se ha salvado donde tantas cosas se derrumbaron gangrenadas o corrompidas...A ellos les está encomendado también el papel más difícil y más crítico en la hora turbulenta de los pueblos, cuando las masas se encrespan agitadas por el soplo violento de la pasión; cuando ruge el motín o estalla el tumulto, cuando los hombres extraviados sienten la ola roja pasando sobre sus ojos...Basta ver quiénes son los que coinciden en pedir su supresión. Ellos saben que la Guardia Civil es uno de los pilares donde se asienta la sociedad, porque frente al avance de la anarquía, la Guardia Civil repite, como consigna, el grito de las resistencias heroicas: «jNo pasarán!»... Y en este forcejeo entre los que resisten y los que atacan cuantos queremos que España sobreviva debemos situarnos al lado de la Guardia Civil para repetir con ella: «¡No pasarán!. ${ }^{25}$

23 AHN-M, Sección Gobernación, leg. 6A. Cuestiones sociales, exp. 21 y 61 . Numerosas denuncias de pueblos como Escalona, Torralbos, Cobeja, Villarejo de Montalbán, Yunclillos, Villanuelas...

24 Idem, leg. 7A, exp. 26.

25 El Castellano, 25/l/1932. Hacemos notar el uso de un slogan que años después será símbolo de la resistencia del pueblo de Madrid. 


\section{LA ACTITUD DE LOS GOBERNADORES CIVILES}

Un aspecto de interés que todavía no ha sido suficientemente estudiado, es la forma en que la actuación de los gobernadores civiles influyó en la deriva violenta de los acontecimientos. Es cierto que se daban unas condiciones sociales y políticas que ineludiblemente parecían conducir en esa dirección, pero conviene analizar en qué grado fueron agravadas por las instrucciones de orden público emanadas desde el Gobierno Civil. ${ }^{26}$ Ya desde la proclamación de la República, la presencia del moderado Miguel Maura en el Gobierno Provisional, ocupando la trascendental cartera de Gobernación, indicaba la obsesión de los nuevos dirigentes por evitar dar muestras de debilidad en un tema tan sensible. Con tal fin se procedió a nombrar a personas afines para ocupar los principales cargos de control político, mientras que en la policía y la guardia civil la tendencia fue al continuismo, probablemente por la ausencia de leales cualificados y por pretender dar la sensación de cambio pacífico.

Esta política conservadora en los nombramientos no era bien vista por las organizaciones de la izquierda, que criticaban la permanencia de antiguos represores monárquicos. Eso ocurrió en la ciudad de Toledo, donde las sociedades obreras protestaron por la continuación en sus cargos del comisario Seseña y del agente Latorre, ${ }^{27}$ represores del tiempo de la dictadura. Distinto fue lo sucedido con los nombramientos de los gobernadores civiles; Maura situó en estos puestos a personas leales que actuasen como agentes de su partido, la Derecha Liberal Republicana.

\section{Cuadro 2}

\begin{tabular}{|l|l|c|}
\hline \multicolumn{1}{|c|}{ Nombre } & \multicolumn{1}{c|}{ Partido } & \multicolumn{1}{c|}{ Tiempo de mandato } \\
\hline José M. ${ }^{a}$ Semprún Gurrea & Derecha Liberal Republicana & $17 / 04 / 1931$ al 16/06/1931 \\
\hline Álvaro Botella Pérez & Radical Socialista & $14 / 06 / 1931$ al 16/09/1931 \\
\hline Luis Fernández de Valderrama & Republicano & $16 / 09 / 1931$ al 21/10/1931 \\
\hline Manuel Asensi Maestre & Republicano Radical & $21 / 10 / 1931$ al 17/06/1932 \\
\hline Juan Serrano Piñana & Acción Republicana & $17 / 06 / 1932$ al 20/02/1933 \\
\hline Isidro Liarte Lausín & Acción Republicana & $25 / 02 / 1933$ al 14/09/1933 \\
\hline Manuel Asensi Maestre & Republicano Radical & $14 / 09 / 1933$ al 28/11/1933 \\
\hline
\end{tabular}

FUENTE: Elaboración propia ${ }^{28}$.

${ }^{26}$ La destrucción de la sede de esa institución durante el asedio del Alcázar dificulta el estudio de dicha cuestión, pues sólo quedan los fondos del AHN-M relativos al Ministerio de la Gobernación y el reflejo de los hechos en la prensa provincial.

27 REQUENA GALLEGO, M., «La clase política y las contiendas electorales en las provincias de Castilla-La Mancha. 1931-1933» en 1. ${ }^{\circ}$ Congreso de Historia de Castilla-La Mancha (Tomo 2), Talavera, Servicio de Publicaciones de la Junta de Castilla-La Mancha, 1988.

28 Las fuentes utilizadas han sido: El Castellano, El Heraldo Toledano y El Heraldo de Toledo. Además, aparecen referencias valiosas en AHN-M, Sección Gobernación, leg. 6A y 38A. 
En Toledo hubo seis gobernadores durante el periodo estudiado, según se aprecia en el cuadro 2. En términos generales, su actuación se caracterizó por las siguientes pautas:

a) La inestabilidad. La presencia en poco más de dos años de seis gobernadores civiles habla por sí sola. Fueron mandatos tan breves como el del cuñado de Miguel Maura, José María Semprún, cuyo nombramiento parecía tener como objetivo su elección como diputado en las Cortes Generales, de modo que, una vez conseguido, se procedió a su sustitución. Igualmente breve fue el mandato de Luis Fernández de Valderrama, si bien en este caso su destitución obedeció a su ineficiencia en el desempeño de su cargo, según veremos más adelante. Lo cierto es que, en esos momentos, Toledo era una de las provincias más complejas para gestionar el orden público. Las presiones continuas de los socialistas por un lado y la de los propietarios agrarios por otro, trazaban una línea intermedia en la que los representantes del Gobierno no supieron situarse. Como consecuencia nunca existió un programa de actuación autónomo, adaptado a las circunstancias del territorio y con suficiente flexibilidad para afrontar cuestiones relevantes.

b) Política represiva y enfrentamientos con las fuerzas de izquierda. Desde la formación del Gobierno Provisional, quedó claro que la preservación del orden público era prioritario para los nuevos gobernantes. Sin embargo, en unos tiempos de grandes transformaciones como aquéllos, era cuestionable que el concepto de orden público se identificara con el que había establecido la Monarquía ${ }^{29}$. La llegada a Toledo del primer gobernador republicano, José María Semprún, aseguraba la identificación con la línea dura del Ministro Miguel Maura. Éste ya había dejado claros sus criterios en una circular emitida pocos días después de los asaltos a edificios religiosos ${ }^{30}$. Las demandas de rigor y dureza en la política de seguridad pública fueron fielmente seguidas desde Toledo, según lo atestiguan las posteriores comunicaciones entre el Gobernador y el Ministerio ${ }^{31}$. Pero el momento álgido de la represión contra las organizaciones de izquierda fue protagonizado por Luis Fernández Valderrama. A su cargo estuvo la nefasta actuación de la guardia civil en los sucesos de Corral de Almaguer ${ }^{32}$, ejemplo de desmesura en el tratamiento de un conflicto que se había iniciado en una simple reunión de obreros en una era, para concluir con la muerte a tiros de cinco campesinos en la plaza mayor del pueblo. Sin duda ese hecho condujo a su destitución y a ser calificado como el nuevo «Martínez Anido». Una política más ecuánime, aunque discutida por los socialistas,

29 GONZÁLEZ CALLEJA, E., «El Estado ante la violencia» en JULIÁ, S., Violencia política en la España del siglo XX, Madrid, Taurus, 2000, pp. 382-387.

${ }^{30}$ AHN-M, Sección Gobernación, leg. 16A. Desórdenes públicos. Exp. 17. Circular n. ${ }^{\circ} 86$ Ministro a Gobernador. Gobierno Provisional asume plenos poderes para atender el bien público y la salud de la República. Con máxima energía. Proceda VE por cuantos medios tenga a su alcance a mantener el Orden Público limpiando la provincia de elementos perturbadores a cuyo fin acordará las necesarias detenciones y expulsiones del territorio de su jurisdicción dando cuenta al ministro.

${ }_{31}$ Idem, exp. 17. Comunicaciones del 5/6/1931 y 9/6/1931 en las que se da cuenta de la detención y expulsión de la provincia, por perturbadoras, de 15 personas.

32 El Castellano, 23-09-1931. 
fue la desarrollada por Manuel Asensi Maestre, el gobernador que más tiempo permaneció en el cargo. Pero los datos nos hablan de claroscuros en su gestión, pues simultaneaba la imposición de sanciones a los propietarios que no respetaban las bases $^{33}$, e incluso solicitaba su encarcelamiento ${ }^{34}$, con una descarada política de propaganda a favor del partido radical y de enfrentamiento con los socialistas ${ }^{35}$. La respuesta de la izquierda fue el desencadenamiento de una campaña organizada que buscaba su cese, para lo que remitieron cartas a Casares Quiroga desde las sociedades obreras, casas del pueblo y delegaciones del partido socialista pidiendo que fuera destituido. ${ }^{36}$ Finalmente la campaña tuvo éxito y Asensi se vio forzado a dimitir. Según él, su dimisión tenía una doble motivación: a) su marginación en la solución del problema campesino que afectaba a Talavera, donde el ministro le había ignorado encargando la gestión a Valdés, alcalde de la ciudad; b) la razón principal parecía residir en la rivalidad creciente entre Lerroux y los socialistas ${ }^{37}$, contienda en la que él había sido un elemento pasivo. Más del agrado del bloque socialista toledano resultaron los gobernadores Álvaro Botella e Isidro Liarte que por el contrario, fueron criticados por los propietarios y la derecha en general.

La conclusión lógica de todo lo anterior es que la labor de los gobernadores de la República en Toledo constituyó un rotundo fracaso. Su naufragio en la gestión del sistema de seguridad y orden público en la provincia era, por otra parte, fiel reflejo de lo que sucedía a escala nacional. El nuevo régimen desarrollaba una política errónea en uno de los ámbitos básicos del poder ejecutivo. La necesaria modernización del sistema de orden público no se produjo y los gobernadores civiles actuaron de la misma forma y con las mismas herramientas que lo habían hecho sus antecesores monárquicos. Y todo ello en una sociedad que poco tenía que ver con la anterior. Con gran sagacidad situaba la cuestión el primer alcalde republicano de Toledo José Ballester Gozalvo, cuando debatía con el gobernador Manuel Asensi Maestre en torno a su dimisión; así definía lo que debía ser un gobernador republicano:

Ser gobernador republicano es seguir procedimientos distintos a los de la monarquía, respetar en todo momento la constitución y que ésta sea en manos del gobernador, el instrumento que ampare los derechos ciudadanos ${ }^{38}$.

33 AHN-M, Sección Gobernación, leg. 7A. Cuestiones sociales. Exp. 26. 22/l/1932. Comunicación Gobernador a Ministro. Imposición de multas de 1000 ptas. a propietarios de Gerindote por no cumplir las bases de trabajo. Son reincidentes y mantienen una posición obstruccionista.

34 Idem, Comunicación Gobernador a Ministro de fecha 16/II/1932. Pide autorización para encarcelar a propietarios de Lucillos que se niegan a cumplir bases. Cree que quieren provocar un conflicto de orden público.

${ }^{35}$ Idem, leg. 38A. Gobernadores. Circulares. Exp. 5. Aparecen numerosas comunicaciones de sociedades obreras y ayuntamientos quejándose de la propaganda a favor de los radicales y en contra de las formaciones de izquierda.

${ }_{36}$ Idem. Que se trataba de una campaña coordinada lo demuestra el hecho de que una mayoría de las notas enviadas por las organizaciones socialistas tenían una redacción idéntica.

37 El Castellano, n. ${ }^{\circ} 7211,15 / \mathrm{VI} / 1932$.

38 Idem, n. ${ }^{\circ} 7214,18 / \mathrm{VI} / 1932$. 


\section{LA POLÍTICA DE ORDEN PÚBLICO}

La intervención de la Guardia Civil fue uno de los rasgos más criticables y destacados de la política de orden público de la II República. Cuestión de notable interés para la historiografía moderna, nos interesa ahora analizar su repercusión en el ámbito local toledano.

El nuevo régimen que nació el 14 de abril de 1931 no tenía como una de sus prioridades la reforma del sistema de orden público de la Monarquía. En consecuencia, desestimó la configuración de un esquema de libertades propio de un régimen democrático, el resultado fue un déficit de derechos colectivos e individuales entre los que la negación del derecho de reunión era el más destacado. Un caso paradigmático en este sentido lo constituye el ya mencionado de Corral de Almaguer, en septiembre de 1931. Es éste el suceso de mayor gravedad de cuantos estamos tratando: cinco campesinos muertos por disparos de la guardia civil. Lo más relevante es que el origen del incidente se halla en una simple reunión de jornaleros, suspendida por un celoso funcionario ${ }^{39}$. Se reunieron en este caso los componentes necesarios para hacer inevitable la tragedia; a saber: una legislación restrictiva del derecho de reunión; un gobernador civil recién llegado e imbuido de la dureza represiva del ministro Miguel Maura ${ }^{40}$, y unas fuerzas de la Guardia Civil sin preparación ni disposición adecuada para hacer frente a situaciones de este tipo.

En relación a lo anterior, numerosas voces republicanas se habían alzado en demanda de nuevos métodos para el mantenimiento del orden público y una adecuación de las técnicas y medios de la Guardia Civil. El máuser, principal arma de dotación, era también el emblema de sus dos mayores defectos: la contundencia incontrolada en la represión y su dependencia militar ${ }^{41}$. Pero los cambios no se produjeron y siguió predominando un modelo político de orden público por encima del profesional. Por eso, lo prioritario en la política de seguridad será la preocupación por la ocupación militar del territorio y la represión de las actividades contrarias al sistema establecido ${ }^{42}$. Todo ello desembocaba en un esquema policial rígido a par-

39 Tanto la prensa local (El Castellano, 21/IX/1931), como la nacional (Heraldo de Madrid, 22/IX/1931 y El Sol, 22/IX/1931) recogieron ampliamente la gravedad de los hechos. En resumen, todo se inició con una asamblea propagandística de los comunistas de Villa de Don Fadrique. Cuando se dirigían a cazar, pasaron por allí el juez, el fiscal y el secretario municipal y ordenaron disolver la reunión. Alterados los obreros capturaron a los tres y los encerraron en el Ayuntamiento; la vigilancia no debió ser muy estricta puesto que escaparon y se refugiaron en casa del primero. Inmediatamente se produjo la respuesta del Gobernador que envió una importante fuerza de la Guardia Civil que, «respondiendo a una agresión», disparó contra una masa de obreros concentrados en la plaza de la localidad. Sobre ella quedaron tendidos cinco jornaleros muertos.

40 Según se indica en el Cuadro 2, Fernández Valderrama había sido nombrado gobernador apenas cinco días antes de los acontecimientos. Es evidente que su rápida sustitución (21/X/1931) tuvo que ver con la enorme repercusión de los hechos a escala nacional.

41 BALLBÉ, M., Orden público y militarismo en la España constitucional, 1812-1983, Madrid, Alianza Editorial, 1983, p. 337.

42 GARRIDO, Diego, La Guardia Civil y el origen del Estado centralista. Barcelona, Crítica, 1982, p. 168 
tir de planes de despliegue muy amplios, pero limitados en hombres. Un ejemplo clarificador sería el «Plan de concentración para grave alteración de Orden Público' de la provincia de Toledo ${ }^{43}$. Se trataba de propósitos imposibles de cumplir eficazmente, puesto que se partía de un número muy reducido de efectivos y medios de transporte escasos y anticuados. En definitiva, se soslayaba la necesaria reforma de un cuerpo que debería haberse orientado hacia la investigación y persecución del delito común. La cadena de incidentes sangrientos sucedidos, entre otros lugares en Toledo, es muestra de las consecuencias que tuvo el grave error de dejar de lado la reforma de un sector tan importante de la Administración policial.

Pero si se quería hacer de la Guardia Civil un cuerpo policial adecuado a la nueva situación política, eran imprescindibles reformas de mayor calado y que tenían que ver con el inconsciente colectivo; había que vencer la impopularidad de este cuerpo entre las masas campesinas. La tarea se presentaba tan descomunal, que probablemente fue la razón que condujo a los políticos republicanos a buscar otra solución. El propio Maura reconoció que otro cuerpo policial mejor dotado y preparado podría enfrentarse más acertadamente a la inseguridad ${ }^{44} \mathrm{y}$, pese a ello, renunció a introducir reformas en dicha institución. La creación de una nueva fuerza de seguridad parecía ser la opción más adecuada. Surgió así la nueva Sección de Asalto. Dotada con sable, pistola y porra pero no con máuser, padecía sin embargo defectos importantes, como el carácter castrense de sus mandos, que muy pronto le impregnará, o la politización de la gran mayoría de sus miembros. Ciertamente el nuevo cuerpo de seguridad alcanzó pronto un notable éxito entre las masas republicanas, y en muy poco tiempo contaba con más de mil guardias y numerosos aspirantes. Y fue precisamente en Toledo donde sufrió sus primeras bajas. A principios de marzo de 1932, en la capital provincial, la Unión Local de Sindicatos (ULS) había declarado una huelga en demanda de medidas contra el paro forzoso. Las manifestaciones de huelguistas y los incidentes se extendieron por la ciudad, y en esas condiciones se produjo la primera intervención de los guardias de asalto. En los enfrentamientos resultaron heridos muy graves los guardias Estera e Ibáñez, que murieron posteriormente. Para la prensa católica los disparos fueron obra de pistoleros comunistas, y de hecho, las detenciones que se produjeron a continuación, afectaron a miembros de dicho grupo, entre ellos el abogado Virgilio Carretero ${ }^{45}$.

Pero el elemento más definitorio de la política de seguridad durante el primer bienio republicano fue sin duda la Ley de Defensa de la República. Aprobada en octubre de 1931, pretendía atender las amenazas que acechaban al nuevo régimen y que, a los ojos del sector más conservador del Gobierno Provisional, ponían en peligro el futuro republicano. En su esencia la nueva norma apoyaba los mé-

${ }^{43}$ AHN-M, Sección Gobernación, leg. 39A. Guardia Civil, exp. 11.

44 BALLBÉ, M., op. cit., p.320.

${ }^{45}$ El Castellano, 7/III/1932, 9/III/1932, 11/III/1932. 
todos tradicionales en la gestión del orden público; se trataba de un recurso a la legislación especial, como se había hecho durante la Monarquía, al mismo tiempo que desechaba la posibilidad de profundizar en el desarrollo de las libertades y de un modelo de seguridad acorde con el sistema democrático. Con acierto ha destacado Manuel Ballbé la inconsistencia legal a que dio lugar la publicación de la ley subrayando la contradicción que se produjo entre dicha ley y el Título III de la Constitución que se aprobó meses después, pues mientras la norma constitucional establecía un régimen garantista de derechos y deberes de los ciudadanos, la Ley de Defensa de la República se situaba en el terreno de la excepcionalidad ${ }^{46}$. La eficacia de esta norma fue muy limitada. Únicamente podemos apuntar que al menos supuso un freno a la influencia del poder militar en el orden público.

Pero el Ministerio tenía el firme propósito de aplicar la ley en toda su potencialidad. En consecuencia remitió circulares al gobierno civil, pidiendo informes sobre personas extremistas de la provincia a las que se les pudiese aplicar dicha ley, ${ }^{47} \mathrm{y}$ demandando el control de la prensa provincial. ${ }^{48} \mathrm{Y}$ en ese sentido, los gobernadores civiles toledanos fueron especialmente sumisos a las instrucciones procedentes de Madrid. El impulso ministerial debió animar al Gobierno Civil a utilizar este instrumento legal de forma abusiva, hasta el punto de que, poco después, fue necesario advertir sobre los excesos que se estaban produciendo en su aplicación; se llegaba incluso a mantener en prisión a detenidos que previamente habían sido excarcelados por el juez, sin calibrar siquiera la gravedad del delito cometido. ${ }^{49}$ Empezó a generalizarse la aplicación de la norma, concebida con carácter excepcional, a cuestiones de índole ordinaria como la mera rivalidad entre propietarios y jornaleros; así actuó el gobernador Manuel Asensi cuando impuso multas de 1.000 pesetas a varios propietarios de Gerindote acusándoles de «reincidencia y obstrucción sistemática» por negarse a cumplir las bases de trabajo. ${ }^{50}$ Pero, mayor celo funcionarial mostró su sustituto, el gobernador Juan Serrano Piñana, cuando remitió al Ministerio de la Gobernación un librillo de papel de fumar confiscado en un estanco de Torrijos, marca «Nacional», que utilizaba en su envoltorio los colores de la bandera monárquica. Sostenía Serrano que dicho librillo «constituía una provocación para los elementos republicanos». ${ }^{51}$

En consecuencia, los instrumentos de los que se dotó la República para estructurar un sistema de seguridad adecuado a la nueva situación no cumplieron las

46 BALLBÉ, M., op. cit. pp. 317-318.

47 AHN-M, Sección Gobernación, leg. 18A. Ley de Defensa de la República, exp.8, 14/1/1932. «Ruego me informe de las personas más extremistas y peligrosas que se encuentran en esa provincia, expresándome el concepto por el cual pueden producir perturbaciones de orden público a fin de aplicar la Ley de Defensa de la República»

48 Idem, exp. 12, 10/VIII/1932. Coincidiendo con la intentona de Sanjurjo, el Ministro solicita el cierre de aquellos periódicos que transmitan mensajes contra la República o de tono «monarquizante».

49 Idem, leg. 40A,exp.10, 26/V/1933. Advertencia del Ministro al Gobernador de que las personas liberadas por los jueces sólo podían ser retenidas en prisión si eran muy peligrosas.

50 Idem, leg. 7A, exp. 26, 22/l/1932.

51 Idem, leg. 18A, exp. 12, 19/VII/1932. 
expectativas previstas. Además, la timidez de las reformas apenas consiguió retocar la superficie de unos problemas que amenazaban la propia supervivencia del régimen.

\section{CONCLUSIONES}

1. Durante los años del bienio republicano reformista tuvo lugar en Toledo un movimiento de concienciación política de gran alcance. Este proceso resultó especialmente llamativo porque se daba en una zona donde la sociedad tradicional parecía inamovible. Partiendo de una situación de injusticia atávica, las clases populares de la provincia depositaron sus esperanzas en el nuevo régimen y se dispusieron a defender lo que consideraban una ocasión histórica. A tal efecto se construyó de la nada y a gran velocidad, una estructura organizativa que canalizase sus reivindicaciones. En muy poco tiempo brotaron en los pueblos sociedades obreras, sindicatos y delegaciones de los partidos de izquierda. Entre los campesinos toledanos, acuciados por un paro muy elevado, empezó a popularizarse el debate político que les familiarizó con principios ideológicos revolucionarios. $Y$ de esa contienda de ideas, a la que se unió la polémica en torno a la praxis, surgió una división en el mundo de la izquierda. Frente a una alternativa moderada y posibilista encabezada por el PSOE y la UGT, se encontraba la línea intransigente del PCE, partidario de ir a la revolución proletaria de manera inmediata. La batalla entre ambas concepciones tomó caracteres preocupantes, que más tarde tendrían una proyección conocida por todos. De esta forma, Toledo se convirtió en la provincia con mayor número de afiliados a sindicatos en sus ramas agrarias, y el nivel de politización de las capas obreras permitió el desarrollo de acciones reivindicativas propias de situaciones revolucionarias. Consecuentemente, las masas rurales se proveían de un cuerpo ideológico que las capacitaría para la lucha social que las enfrentaba a los propietarios agrícolas y a la derecha sociológica. Ésta también había pasado por un proceso, si no de concienciación, sí de reconstrucción del contenido ideológico. El derrumbe de la derecha monárquica forzó la aparición de nuevas alternativas políticas, capaces de aglutinar el apoyo de las siempre cuantiosas masas derechistas de la provincia. Su trabajo en pueblos y parroquias de todo Toledo terminó fructificando en el triunfo electoral de noviembre de 1933.

2. Cuando las masas proletarias adquirieron conciencia de su situación, iniciaron el camino hacia la transformación social. El cambio político permitió llevar más lejos las demandas obreras; objetivos de corto plazo cedieron el paso a otros de largo alcance, de carácter estructural. El reforzamiento de las posiciones de izquierda y la vulgarización de usos violentos favorecían la vía de las conquistas sociales. De otra parte, la oposición del renovado bloque derechista, unido ante la presión obrera, dio lugar al desencadenamiento de infinidad de incidentes en los que la violencia fue elemento esencial. Huelgas, ocupaciones de tierras, pueblos 
sublevados... actos todos ellos que terminaban siendo reprimidos contundentemente por la Guardia Civil. Es una agitación que se nutre de acciones violentas propias del siglo anterior, junto con otras modernas que recurren a la insurrección y al enfrentamiento con las fuerzas policiales. Treinta y dos muertos y más de 60 heridos en poco más de dos años fue el trágico producto de estos tiempos. Estas cifras corrigen al alza las hasta ahora existentes, y aún hemos dejado algunas más, pendientes de ulteriores investigaciones, puesto que, de momento resultan dudosas.

3. La agitación social que vivió Toledo entre 1931 y 1933 no se explicaría sin la intervención de un factor decisivo: la errónea política de orden público de la República. La gestión de esta parte de la Administración por los sectores más conservadores del Gobierno sentó las bases de una línea de actuación anclada en los hábitos del régimen anterior. En la zona geográfica que estudiamos, los efectos de esta política incrementaron la gravedad de la situación. Tres pilares básicos de la acción del gobierno fracasaron en sus funciones. 1) Los gobernadores civiles, de manera general, pecaron de inestabilidad y falta de compromiso con un esquema de orden público verdaderamente democrático. Además, en no pocas ocasiones, su permanente recurso a la contundencia represiva concluía agravando las acciones de protesta obrera que pretendía solventar. Así pues, fueron incapaces de implicarse en la provincia y comprender los complejos problemas sociales que afectaban a buena parte de la población. 2) Mientras tanto la Guardia Civil siguió siendo el más importante instrumento de la acción ejecutiva. Su identificación con los intereses de la derecha y su tradicional abuso de la represión indiscriminada la convertía en enemiga de la clase trabajadora, eliminando cualquier capacidad mediadora. 3) Tampoco la creación de un nuevo cuerpo policial, la Guardia de Asalto, resolvió el problema de la presencia de los militares en el orden público ni la politización de quienes debían preservarlo. La Ley de Defensa de la República constituía el brazo legal que debería dotar al régimen del 14 de abril de estabilidad y seguridad. Sin embargo, su escasa eficacia y la contradicción que se estableció entre esa ley excepcional y la nueva constitución republicana condicionan nuestra visión sobre la misma. Por tanto, concluyamos que la política de seguridad y orden público de la Segunda República jugó un papel determinante en la dinámica de agitación social que tuvo lugar en Toledo durante el primer bienio republicano. Unas fuerzas de seguridad renovadas y con métodos adecuados podrían haber limitado el alcance de los conflictos que hemos referido. Lejos de ello, la actuación cotidiana de esas fuerzas, bajo la dirección política del Gobierno Civil, convirtió meros incidentes de orden público en actos de violencia extrema que retroalimentaban el odio de los campesinos hacia la Guardia Civil.

En definitiva, aunque sólo tuviésemos en cuenta el aspecto cuantitativo de los sucesos violentos que hemos estudiado, podríamos afirmar que Toledo fue una provincia de primera línea en la lucha política y social durante los primeros años de la Segunda República. Pero si además revisamos la tipología de los sucesos, podemos concluir que nos hallaríamos, cuanto menos, en el inicio de un proceso 
de revolución social. Acotándolo en el tiempo, diríamos que el primer bienio representó en Toledo el prólogo de un fase revolucionaria que, obviando el período derechista de la República, tendría continuación en la primavera revolucionaria de 1936 y en los años de la guerra civil. 